\title{
Hormonal therapy with estradiol and drospirenone improves endothelium-dependent vasodilation in the coronary bed of ovariectomized spontaneously hypertensive rats
}

\author{
M.V. Borgo ${ }^{1}$, E.R.G. Claudio ${ }^{1}$, F.B. Silva ${ }^{1}$, W.G. Romero ${ }^{1}$, S.A. Gouvea ${ }^{1}$, M.R. Moysés ${ }^{1}$, \\ R.L. Santos ${ }^{1}$, S.A. Almeida ${ }^{1}$, P.L. Podratz ${ }^{2}$, J.B. Graceli ${ }^{2}$ and G.R. Abreu ${ }^{1}$ \\ ${ }^{1}$ Departamento de Ciências Fisiológicas, Centro de Ciências da Saúde, Universidade Federal de Espírito Santo, \\ Vitória, ES, Brasil \\ ${ }^{2}$ Departamento de Morfologia, Centro de Ciências da Saúde, Universidade Federal do Espírito Santo, \\ Vitória, ES, Brasi
}

\begin{abstract}
Drospirenone (DRSP) is a progestin with anti-aldosterone properties and it reduces blood pressure in hypertensive women. However, the effects of DRSP on endothelium-dependent coronary vasodilation have not been evaluated. This study investigated the effects of combined therapy with estrogen (E2) and DRSP on endothelium-dependent vasodilation of the coronary bed of ovariectomized (OVX) spontaneously hypertensive rats. Female spontaneously hypertensive rats $(n=87)$ at 12 weeks of age were randomly divided into sham operated (Sham), OVX, OVX treated with E2 (E2), and OVX treated with E2 and DRSP (E2 + DRSP) groups. Hemodynamic parameters were directly evaluated by catheter insertion into the femoral artery. Endothelium-dependent vasodilation in response to bradykinin in the coronary arterial bed was assessed using isolated hearts according to a modified Langendorff method. Coronary protein expression of endothelial nitric oxide synthase and estrogen receptor alpha $(E R-\alpha)$ was assessed by Western blotting. Histological slices of coronary arteries were stained with hematoxylin and eosin, and morphometric parameters were analyzed. Oxidative stress was assessed in situ by dihydroethidium fluorescence. Ovariectomy increased systolic blood pressure, which was only prevented by E2+DRSP treatment. Estrogen deficiency caused endothelial dysfunction, which was prevented by both treatments. However, the vasodilator response in the E2 + DRSP group was significantly higher at the three highest concentrations compared with the OVX group. Reduced ER- $\alpha$ expression in OVX rats was restored by both treatments. Morphometric parameters and oxidative stress were augmented by OVX and reduced by E2 and E2+DRSP treatments. Hormonal therapy with E2 and DRSP may be an important therapeutic option in the prevention of coronary heart disease in hypertensive post-menopausal women.
\end{abstract}

Key words: Menopause; Hypertension; Hormone therapy; Drospirenone; Coronary reactivity

\section{Introduction}

Coronary heart disease (CHD) is a major cause of morbidity and mortality worldwide (1), and hypertension is established as one of the main risk factors for the development of CHD (2). Prior to menopause, women exhibit lower blood pressure (BP) compared with age-matched men. However, aging and decreased circulating estrogen (E2) levels are accompanied by increased BP, which contributes to a greater prevalence of hypertension and an increased prevalence of $\mathrm{CHD}$ during the post-menopausal period (3), suggesting a protective role for E2. Experimental studies analyzing the effects of estrogen replacement therapy in ovariectomized (OVX) rats have demonstrated many beneficial effects on the cardiovascular system. These beneficial effects include the capacity to lower BP in normotensive and hypertensive rats (4-6), reduce oxidative stress (4), prevent endothelial dysfunction, improve endothelium-dependent coronary vascular reactivity, and protect against vascular remodeling in early-stage hypertensive rats $(7,8)$.

However, randomized clinical trials such as the Women's Health Initiative and the Heart and Estrogens/ progestin Replacement Study, which analyzed primary and secondary prevention, respectively, have failed to

Correspondence: E.R.G. Claudio: <erick_edf@yahoo.com.br> 
demonstrate such cardiovascular benefits. The conjugated equine E2 plus medroxyprogesterone acetate (MPA) arm of the Women's Health Initiative was prematurely stopped because of the high risk and incidence of CHD, venous thromboembolism, and cancer (9). Nevertheless, although some questions and concerns arose from these studies, the current use of hormone replacement therapy with or without progestins following menopause remains strongly debated.

The undesirable side effects that occur with the use of progestins can manifest because of their interactions with other steroid receptors, such as androgen, estrogen, and glucocorticoid receptors (10). In female swine, progesterone impairs endothelium-dependent relaxation in coronary arteries associated with decreased endothelial nitric oxide synthase (eNOS) immunoreactivity and augmented superoxide production (11). Similarly, MPA, a highly androgenic progestin, reduces endothelial aortic reactivity in aldosterone salt-treated rats after long-term administration. These effects did not occur in groups treated with E2 and drospirenone (DRSP) (12). These results suggest detrimental vascular effects from MPA treatment, and a neutral or beneficial effect from DRSP.

In contrast to other synthetic progestins, DRSP is a progestin that is derived from $17 \alpha$-spironolactone and has anti-androgenic and anti-aldosterone effects. These properties make DRSP the progestin with the most similar effects to natural progesterone, with the added benefit of a BP-lowering effect $(10,13)$. DRSP has eight times the antialdosterone potency of spironolactone, which is a result of its affinity for the mineralocorticoid receptor (MR) $(14,15)$. Previous studies have indicated that combined E2 and DRSP therapy reduces BP in post-menopausal women with stages 1 to 2 hypertension and in young healthy normotensive women $(16,17)$, although other studies found no significant changes $(18,19)$.

Although the vascular benefits of E2 have been described, the effects of combined therapy with E2 and DRSP on endothelium-dependent coronary vascular reactivity are unknown. Because of the BP-lowering characteristic of DRSP, we hypothesized that DRSP does not impair endothelium-mediated vasodilation in the coronary bed of OVX spontaneously hypertensive rats, as already demonstrated with other synthetic analogues of progesterone. Therefore, the aims of this study were to analyze the effects of combined therapy with E2 and DRSP on endothelium-dependent coronary vascular vasodilation in response to bradykinin, as well as on coronary vascular remodeling and oxidative stress in OVX spontaneously hypertensive rats.

\section{Material and Methods}

\section{Animals \\ Female, spontaneously hypertensive rats at 12 weeks of age, weighing 160-200 g, were provided by the university}

facility. All procedures were approved by the Institutional Ethical Committee for Animal Care and Use of the Universidade Federal do Espírito Santo (protocol \#023/ 2012). Experiments were conducted in accordance with the Guide for the Care and Use of Laboratory Animals published by the US National Institutes of Health (NIH Publication, revised 1996). The rats were kept in collective cages with free access to water and standard rat chow (Purina Labina ${ }^{\circledR}$, Brazil) under controlled temperature $\left(22-24^{\circ} \mathrm{C}\right)$, humidity $(40-60 \%)$, and light-dark cycle (12-12 h). At the time of ovariectomy, the rats were randomly divided into 4 groups as follows ( $n=87$ ): sham control (Sham); OVX; OVX treated with estrogen (E2), and OVX treated with estrogen plus DRSP (E2+DRSP).

\section{Ovariectomy}

Ovariectomy was performed under general anesthesia with an intraperitoneal (ip) injection of $80 \mathrm{mg} / \mathrm{kg}$ ketamine and $12 \mathrm{mg} / \mathrm{kg}$ xylazine. A bilateral dorsolateral incision was made through the skin, and the underlying muscle was dissected to locate the ovary and fallopian tube. The tube was ligated with a suture line and the ovary was removed. The muscle and skin were then sutured with an absorbable suture. After the surgery, rats received an injection of antibiotic $(2.5 \%$ enrofloxacin, $0.1 \mathrm{~mL}$, intramuscularly). Sham rats were incised and sutured, but the ovary was left intact.

\section{Hormone therapy}

E2 therapy was performed by subcutaneous injections $(0.1 \mathrm{~mL})$ containing $0.05 \mathrm{mg} / \mathrm{kg}$ per day of $17 \beta$-estradiol (Sigma, USA) diluted in corn oil, three times per week, as previously described (20). Rats that were treated with DRSP and $17 \beta$-estradiol combined therapy received 0.03 and $0.06 \mathrm{mg} / \mathrm{kg}$ per day, respectively, administered daily by gavage, starting 7 days after OVX during 6 weeks. The choice of these concentrations was made to mimic the dosage used for hormonal therapy in postmenopausal women. Rats that did not receive any of the therapies had the same volume either injected (corn oil) or gavaged (saline). The effectiveness of the ovariectomy and experimental therapies were assessed by uterine wet weight and the uterine weight to body weight ratio.

\section{Hemodynamic measurements}

At the end of the experimental protocol, rats were anesthetized with ketamine and xylazine (50 and 10 $\mathrm{mg} / \mathrm{kg}$, ip). For direct measurement of systolic BP, diastolic $\mathrm{BP}$, mean arterial pressure, and heart rate, a polyethylene (PE-50) catheter (attached to PE-10 tubing) was inserted into the femoral artery and tunneled to the dorsal neck region. The rats remained in a fasted state until between 7:00 and 8:00 am of the next day to obtain direct measurements of $\mathrm{BP}$ in awake and unrestrained rats (TRA021 BP transducer coupled to an ML 110 Amplifier; ADInstruments, Australia). BP and heart rate values were 
calculated for each rat from continuous recordings averaged over a 30-min period.

\section{Isolation of coronary arteries}

The rats were sacrificed by decapitation. The thoracic cavity was opened, and the heart was removed and placed in cold Krebs-Henseleit buffer solution: $115 \mathrm{mM} \mathrm{NaCl}, 25 \mathrm{mM}$ $\mathrm{NaHCO}_{3}, 4.7 \mathrm{mM} \mathrm{KCl}, 1.2 \mathrm{mM} \mathrm{MgSO}_{4} .7 \mathrm{H}_{2} \mathrm{O}, 2.5 \mathrm{mM} \mathrm{CaCl}_{2}$, $1.2 \mathrm{mM} \mathrm{KH}_{2} \mathrm{PO}_{4}, 11 \mathrm{mM}$ glucose, and $0.01 \mathrm{mM} \mathrm{Na}{ }_{2}$ EDTA at $\mathrm{pH} 7.4$ during the dissection procedure. The left anterior descending branch of the left coronary artery and the septal branch were isolated from surrounding ventricular muscle tissue with a dissection microscope (M900; DF Vasconcelos, Brazil) and then snap frozen in liquid nitrogen. The samples were maintained at $-80^{\circ} \mathrm{C}$ until later use.

\section{Isolated heart preparation (modified Langendorff method)}

To assess coronary perfusion pressure (CPP) and endothelium-dependent vasodilation ( $n=5-6$ per group), the rats were anesthetized with chloral hydrate $(40 \mathrm{mg} / \mathrm{kg}$, ip). The heart was excised and immediately perfused at a constant flow rate. Studies on the coronary vascular bed were performed on whole hearts using a modified Langendorff preparation for perfused isolated hearts as previously described (21). Briefly, using a Langendorff apparatus (Hugo Sachs Electronics, Germany), the isolated hearts were perfused with modified Krebs solution (120 mM NaCl, $1.25 \mathrm{mM} \mathrm{CaCl} 2.2 \mathrm{H}_{2} \mathrm{O}, 5.4 \mathrm{mM} \mathrm{KCl}, 2.5 \mathrm{mM} \mathrm{MgSO}_{4} .7 \mathrm{H}_{2} \mathrm{O}$, $2.0 \mathrm{mM} \mathrm{NaH}_{2} \mathrm{PO}_{4} \cdot \mathrm{H}_{2} \mathrm{O}, 27.0 \mathrm{mM} \mathrm{NaHCO}_{3}, 1.2 \mathrm{mM} \mathrm{Na}_{2} \mathrm{SO}_{4}$, $0.03 \mathrm{mM}$ EDTA, and $11 \mathrm{mM}$ glucose), equilibrated with a $95 \%$ oxygen and $5 \%$ carbon dioxide mixture. This was performed at a controlled pressure of $100 \mathrm{mmHg}$ to yield a $\mathrm{pH}$ of 7.4 , and perfused at a rate of $10 \mathrm{~mL} / \mathrm{min}$ at $37^{\circ} \mathrm{C}$ with a peristaltic pump (MS-Reglo 4 channels; Hugo Sachs Electronics). A fluid-filled balloon was introduced into the left ventricle through a steel cannula with a latex balloon and connected to a TPS-2 Statham transducer (Incor, Brazil) to measure the isovolumetric force. The balloon was pressurized with a spindle syringe until it reached a preload of $10 \mathrm{mmHg}$. CPP was monitored with a TPS-2 Statham transducer connected to a sidearm of the aortic perfusion catheter. After a 40-min stabilization period, baseline CPP was measured. Endothelium-dependent vasodilation was randomly analyzed in the coronary arterial bed by bolus administration of $0.1 \mathrm{~mL}$ bradykinin $\left(10^{-10}\right.$ to $\left.10^{-6} \mathrm{M}\right)$.

\section{Western blotting}

The coronary arteries were pooled with frozen tissue from 3 rats (considered as $n=1$ ), and the total number of pooled samples per group was $n=4$. The samples were homogenized in lysis buffer containing $150 \mathrm{mM} \mathrm{NaCl}$, $50 \mathrm{mM}$ Tris- $\mathrm{HCl}, 5 \mathrm{mM}$ EDTA, $2 \mathrm{mM} \mathrm{Na}$, and $1 \mathrm{mM} \mathrm{MgCl}_{2}$ plus protease inhibitors (Sigma Fast, USA). The protein concentration was determined by the Lowry method (22) and bovine serum albumin was used as the standard.
Equal amounts of protein were denatured and separated by $10 \%$ sodium dodecyl sulfate-polyacrylamide gel electrophoresis and transferred onto a polyvinylidene fluoride membrane (Millipore, Germany). The membranes were blocked with $5 \%$ bovine serum albumin at room temperature in TBS buffer plus Tween $20(0.1 \%)$ before incubation with monoclonal anti-mouse for eNOS (1:1500; BD Biosciences, USA), polyclonal anti-mouse for estrogen receptor alpha $(E R-\alpha)$ (1:500; Santa Cruz Biotechnology, USA), and polyclonal anti-mouse for $\beta$-actin (1:1500; Sigma). After washing, the membranes were incubated with an alkaline phosphatase conjugated anti-mouse IgG (1:3000; Abcam Inc., USA). The bands were visualized using an NBT/BCIP system (nitroblue tetrazolium/ 5-bromo-4-chloro-3-indolyl-1-phosphate; Invitrogen, USA) and quantified using ImageJ software (National Institutes of Health, USA).

\section{Histomorphometry}

After perfusion fixation, the septal branch of the coronary artery was dissected free of surrounding tissue as described above. Frozen samples $(n=4)$ from the coronary artery in OCT compound were cut into 8- $\mu \mathrm{m}$ thick sections and mounted on gelatin coated glass slides. The sections were stained with hematoxylin and eosin. The histomorphometric image analysis system consisted of a digital camera (Axio-Cam ERc 5S, Zeiss, Germany) coupled to a light microscope (Olympus AX70; Olympus, USA). High-resolution images $(2048 \times 1536$ pixels buffer) were captured using a Carl Zeiss AxioVision Rel. 4.8 (Germany). Photomicrographs were obtained using a $20 \times$ objective, and the total vascular area, lumen area, vessel wall area, and wall/lumen area were calculated with the area measure tool of AxioVision Rel. 4.8.

\section{Detection of superoxide production (dihydroethidium fluorescence)}

Unfixed frozen sections from the coronary arteries $(n=4)$ were cut into $8-\mu m$-thick sections and mounted on gelatin-coated glass slides. To detect superoxide, samples were incubated with the oxidative fluorescent dye dihydroethidium (DHE, $2 \mu \mathrm{mol} / \mathrm{L}$ ) in a modified Krebs's solution (containing $20 \mathrm{mM}$ HEPES) housed in a lightprotected humidified chamber at $37^{\circ} \mathrm{C}$ for $30 \mathrm{~min}$. The intensity of fluorescence was detected at $585 \mathrm{~nm}$ and quantified in the tissue sections using a confocal fluorescent microscope (Leica DM 2500 TI; Nikon Instruments Inc., USA) by an investigator who was blind to the experimental protocol.

\section{Statistical analysis}

Data are reported as means \pm SE. One- and two-way ANOVAs were used when appropriate. Tukey's post hoc test was used for multiple comparisons. Differences were considered to be significant when $\mathrm{P}<0.05$. 


\section{Results}

\section{Surgery and efficacy of hormonal therapy}

To verify the estrogenic status of the rats, following sacrifice, the uterus was removed and weighed dry. In the OVX group, the weight of the uterus and the uterus to body weight ratio were lower compared with those in the Sham group (both $\mathrm{P}<0.05$ ). Both treatments prevented atrophy of the uterus, and the weight of the uterus and the uterus to body weight ratio were significantly greater with both treatments compared with OVX $(P<0.05)$, indicating the efficacy of hormonal therapy (Table 1).

\section{Hemodynamic measurements and plasma electrolyte concentrations}

Systolic BP in hypertensive rats after ovariectomy was significantly higher than that in the Sham group $(P<0.05)$. Moreover, both treatments restored systolic BP to control levels, but only the E2 + DRSP group reached statistical significance $(P<0.05$ vs OVX). However, heart rate, diastolic BP, and mean arterial pressure were not significantly different among the groups (Table 1). There were no significant differences in plasma sodium and potassium concentrations among the groups (Table 1).

\section{Baseline CPP and endothelium-dependent vasodilator response to bradykinin}

Baseline CPP was significantly reduced in the OVX group compared with the Sham group $(P<0.05)$. Endothelium-dependent coronary vasodilation in response to bradykinin showed an impaired response in the OVX group compared with the Sham group $(P<0.05$; Figure 1A). However, this impairment was restored by estradiol treatment alone or in combination with DRSP compared with OVX rats $(P<0.05$; Figure $1 \mathrm{~B})$. Moreover, combined therapy with DRSP improved the effects of E2 because the endothelium-dependent response was significantly higher at the three highest concentrations compared with the OVX group, and was significantly higher compared with the E2 group at the concentration of $10^{-7} \mathrm{M}(\mathrm{P}<0.05)$.

\section{Coronary expression of eNOS and ER- $\alpha$}

Protein expression of eNOS did not differ among the groups (Figure 2A). We evaluated the effects of ovariectomy and experimental treatments on ER- $\alpha$ protein expression because of the known effects of ER- $\alpha$ activation on enhancement of eNOS activity. Ovariectomy led to a significant reduction in $\mathrm{ER}-\alpha$ protein expression $(P<0.05)$, which was restored by both treatments (both $\mathrm{P}<0.05$ vs OVX; Figure 2B).

\section{Morphometric assessment}

We performed morphometric analysis to analyze the effects of ovariectomy and experimental treatments on vascular remodeling in coronary arteries (Figure 3). The total vascular area, vessel wall area, and lumen area were augmented in the OVX group compared with the Sham group $(P<0.05)$. However, E2 and E2 + DRSP treatments prevented these changes, and these areas were maintained at the same level as in the Sham group and reduced compared with the OVX group $(P<0.05)$. The wall to lumen ratio was reduced in the OVX group compared with the Sham group $(P<0.05)$ because of higher vessel wall and lumen areas. Only E2 + DRSP treatment resulted in a higher wall to lumen ratio compared with the OVX group $(P<0.05)$.

\section{DHE fluorescence}

To evaluate the effects of treatments on vascular oxidative stress in situ, we detected superoxide anion

Table 1. Body weight, estrogenic status, hemodynamic parameters, and plasma electrolyte concentrations.

\begin{tabular}{lcccc}
\hline & Sham $(\mathrm{n})$ & OVX $(\mathrm{n})$ & E2 $(\mathrm{n})$ & E2 + DRSP $(\mathrm{n})$ \\
\hline BW $(\mathrm{g})$ & $189 \pm 3(21)$ & $231 \pm 4^{*}(22)$ & $176 \pm 2^{+*}(22)$ & $198 \pm 3^{+}(22)$ \\
UW $(\mathrm{mg})$ & $345 \pm 36(21)$ & $159 \pm 21^{*}(22)$ & $280 \pm 11^{+}(22)$ & $303 \pm 22^{+}(22)$ \\
UW/BW $(\mathrm{mg} / \mathrm{g})$ & $1.81 \pm 0.18(21)$ & $0.69 \pm 0.1^{*}(22)$ & $1.58 \pm 0.07^{+}(22)$ & $1.53 \pm 0.1^{+}(22)$ \\
HR $(\mathrm{bpm})$ & $347 \pm 14(7)$ & $344 \pm 19(8)$ & $366 \pm 5(7)$ & $335 \pm 14(9)$ \\
SBP $(\mathrm{mmHg})$ & $176 \pm 5(7)$ & $197 \pm 4^{*}(8)$ & $178 \pm 7(7)$ & $173 \pm 4^{+}(9)$ \\
DBP $(\mathrm{mmHg})$ & $110 \pm 4(7)$ & $116 \pm 4(8)$ & $108 \pm 5(7)$ & $109 \pm 7(9)$ \\
MAP $(\mathrm{mmHg})$ & $133 \pm 4(7)$ & $143 \pm 3(8)$ & $131 \pm 5(7)$ & $130 \pm 6(9)$ \\
CPP $(\mathrm{mmHg})$ & $126 \pm 3(5)$ & $107 \pm 5^{*}(6)$ & $131 \pm 5^{+}(6)$ & $123 \pm 3(6)$ \\
Plasma Na+ (mEq/L) & $147.7 \pm 0.67(7)$ & $147.3 \pm 0.25(8)$ & $146.8 \pm 1.44(7)$ & $146 \pm 0.71(9)$ \\
Plasma K $(\mathrm{mEq} / \mathrm{L})$ & $3.63 \pm 0.09(7)$ & $3.3 \pm 0.06(8)$ & $4.05 \pm 0.35(7)$ & $3.54 \pm 0.14(9)$ \\
\hline
\end{tabular}

Data are reported as means \pm SE and number within parentheses. OVX: ovariectomized; E2: estrogen; DRSP: drospirenone. BW: body weight; UW: uterine weight; HR: heart rate; SBP: systolic blood pressure; DBP: diastolic blood pressure; MAP: mean arterial pressure; CPP: baseline coronary perfusion pressure. ${ }^{*} \mathrm{P}<0.05$ compared to Sham; ${ }^{+} \mathrm{P}<0.05$ compared to OVX; ${ }^{\star} \mathrm{P}<0.05$ compared to DRSP (one-way ANOVA followed by Tukey's post hoc test). 

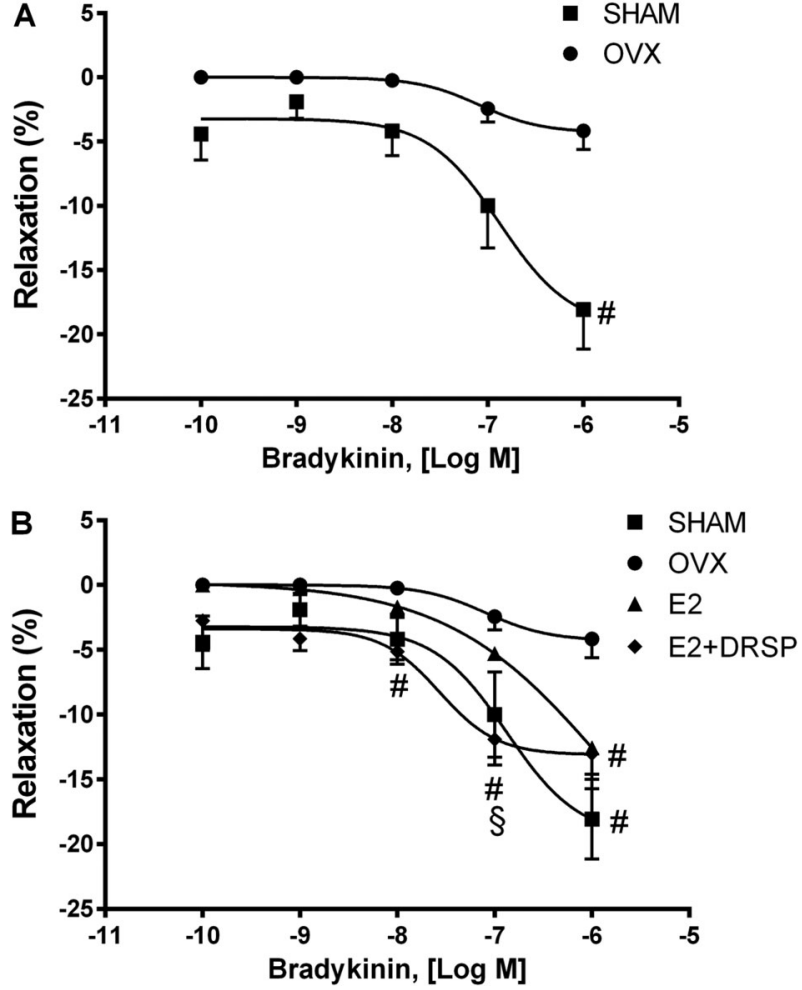

Figure 1. Endothelium-dependent coronary vasodilation with bradykinin. Vasodilation caused by estrogen deficiency $(A)$. Effects of E2 and E2 + DRSP treatments on coronary vascular function $(B)$ in ovariectomized spontaneously hypertensive rats. Data are reported as means \pm SE ( $n=5-6$ per group). OVX: ovariectomized; E2: estrogen; DRSP: drospirenone. ${ }^{\#} \mathrm{P}<0.05$ compared to OVX, ${ }^{\$} \mathrm{P}<0.05$ compared to E2 (two-way ANOVA followed by Tukey's post hoc test).

production by the DHE method (Figure 4). Formation of superoxide anion was increased in the coronary arteries of OVX rats compared with Sham group $(P<0.05)$, which could contribute to oxidative stress and reduced $\mathrm{NO}$
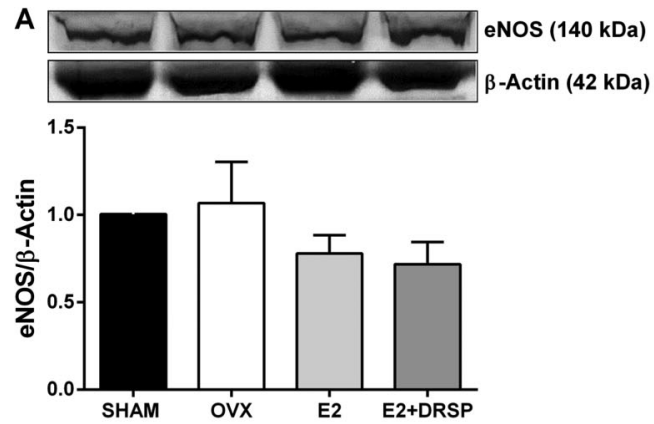

bioavailability. Estradiol alone or in combination with DRSP was able to reduce superoxide formation $(P<0.05)$ to a similar level observed in the Sham group.

\section{Discussion}

The main findings of this study were as follows: $i)$ E2 therapy and combined therapy with E2 and DRSP restored endothelial dysfunction caused by estrogen deficiency in hypertensive rats; ii) E2 + DRSP improved endothelium-dependent coronary vascular reactivity, and iii) DRSP did not impair the estrogenic actions related to prevention of remodeling and vascular oxidative stress.

A decline in plasma E2 concentrations following OVX can cause elevated BP in normotensive rats and exacerbate the hypertensive framework of hypertensive animals $(4-6,23)$, as observed in our study. This finding suggests an important role for E2 on regulation of BP. Based on this finding and the fact that hypertension is an independent risk factor for CHD, women in the post-menopausal period are much more prone to develop this disease, mainly when they are hypertensive. Therefore, determining therapies that can contribute to improvement of this condition, especially considering the particular conditions of the postmenopausal period, is extremely important.

A previous clinical study evaluated the antihypertensive effects of DRSP in post-menopausal women with stages 1 to 2 hypertension (16). This study showed that DRSP at concentrations of 2 and $3 \mathrm{mg}$ conjugated with E2 significantly reduced BP without altering serum potassium concentrations and increasing serum aldosterone concentrations. Similar results were found in another study where $2 \mathrm{mg}$ of DRSP caused a reduction in both systolic and diastolic BP (24).

The BP-lowering effect of DRSP is related to its antialdosterone property, which is characterized by inhibition of the MR. This feature has fundamental importance in the regulation of $\mathrm{BP}$. This is because in addition to inhibiting salt and water retention in the kidneys, MR directly

B
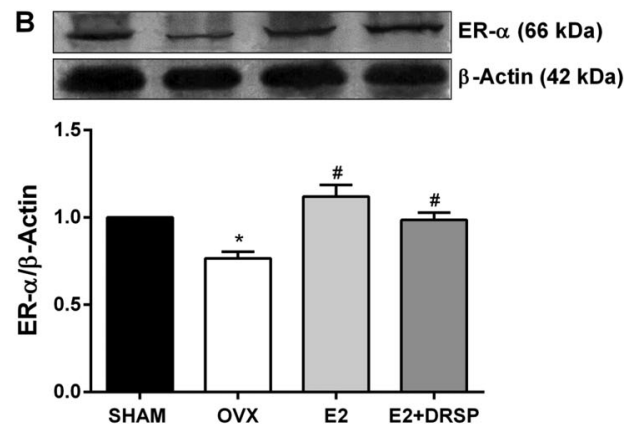

Figure 2. Protein expression of endothelial nitric oxide synthase (eNOS) $(A)$ and estrogen receptor alpha $(E R-\alpha)(B)$ in coronary arteries from ovariectomized spontaneously hypertensive rats. Data are reported as means $\pm S E$ ( $n=4$ per group). OVX: ovariectomized; E2: estrogen; DRSP: drospirenone. ${ }^{*} \mathrm{P}<0.05$ compared to Sham, ${ }^{\#} \mathrm{P}<0.05$ compared to OVX (one-way ANOVA followed by Tukey's post hoc test). 

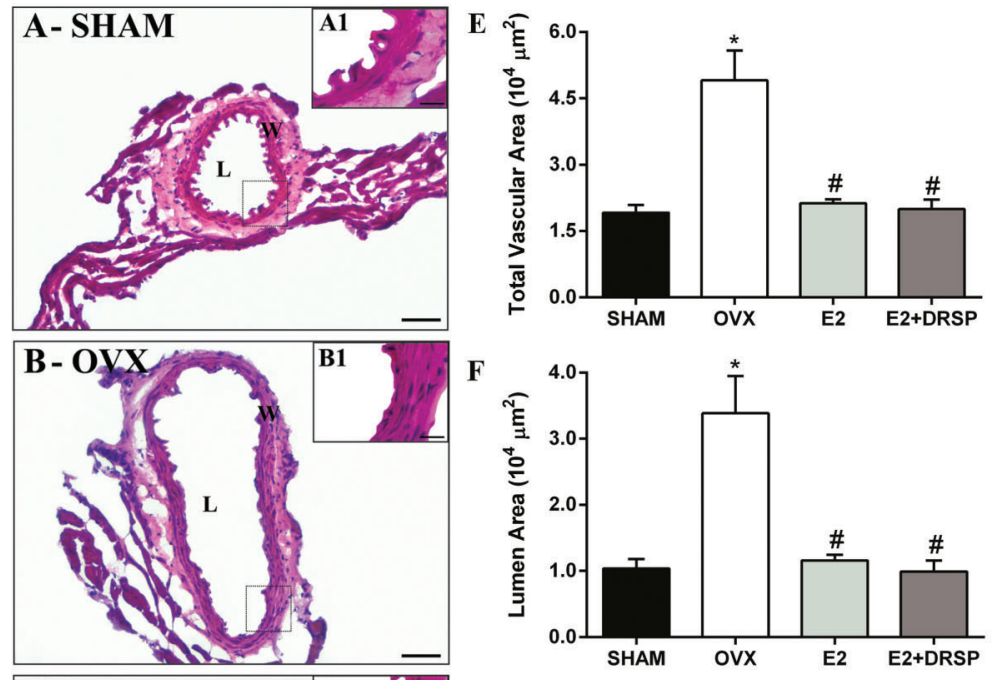

Figure 3. Histomorphometric analysis of coronary arteries from ovariectomized spontaneously hypertensive rats. Representative images of histological slices of the coronary arteries: SHAM ( $A$ and $A 1)$, OVX ( $B$ and $B 1)$, E2 ( $C$ and $C 1)$, DRSP $(D$ and $D 1)$ groups. Total vascular area $(E)$, lumen area $(F)$, vessel wall area $(G)$, and the wall to lumen ratio $(H)$ are reported as means \pm SE ( $n=4$ per group). OVX: ovariectomized; E2: estrogen; DRSP: drospirenone; L: vessel lumen; $\mathrm{W}$ : vessel wall; total vascular area: $\mathrm{L}+\mathrm{W}$ area.

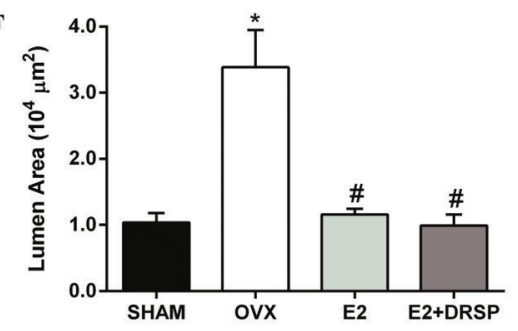
${ }^{*} \mathrm{P}<0.05$ compared to Sham, ${ }^{\#} \mathrm{P}<0.05$ compared to OVX (one-way ANOVA followed by Tukey's post hoc test). Bars: 50 and $20 \mu \mathrm{m}$.
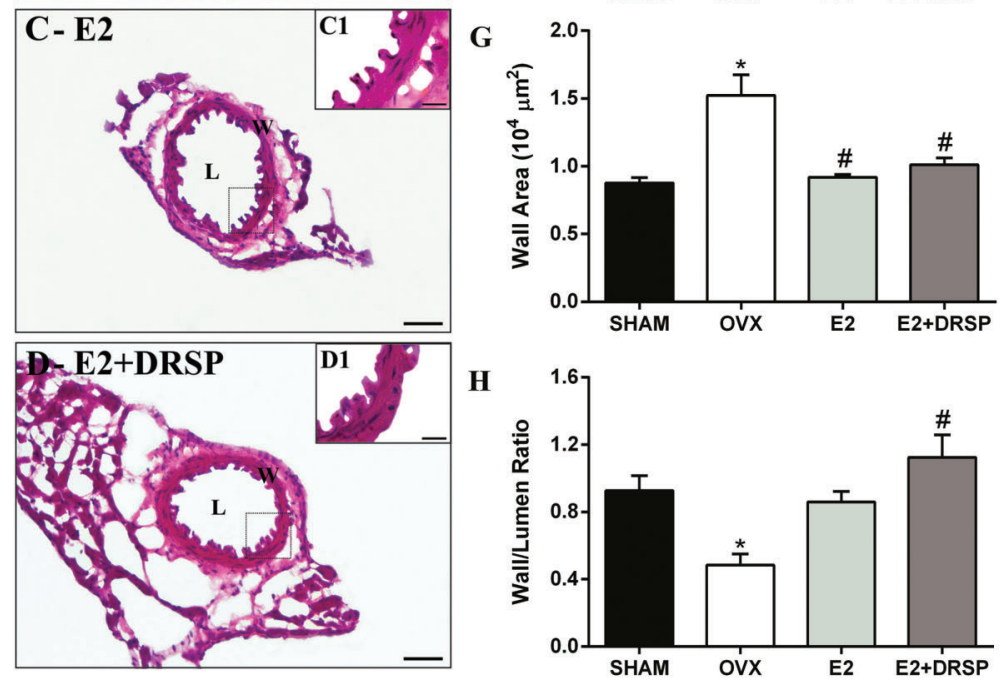

regulates BP in vascular smooth muscle cells (25). McCurley et al. (25) showed that systolic BP in mice with specific deletion of MR in vascular smooth muscle cells was significantly lower compared with that in control animals. This lower systolic BP was maintained, even when the mice aged and were stimulated with angiotensin II infusion. Therefore, the BP-lowering effects of DRSP may be of great therapeutic value for hypertensive women in the post-menopausal period.

In the current study, although CPP was decreased in OVX rats, endothelium-dependent vasodilation in response to bradykinin was extremely reduced in this group. This finding clearly indicates a worsening of endothelial function associated with estrogen deficiency in spontaneously hypertensive rats. This finding was confirmed by morphometric images, where a lack of the vascular endothelial layer in the OVX group (Figure 3B) was observed. Moreover, the lack of E2 increased vascular oxidative stress, as demonstrated by DHE staining. Indeed, OVX can increase oxidative stress independently of blood pressure levels. $A$ reduction in levels of $E 2$, which is a known antioxidant hormone, increases the activity of pro-oxidant generating pathways, such as NADPH oxidase (26), and decreases the protein expression of antioxidant enzymes $(7,27)$. Therefore, decreased bioavailability of nitric oxide (NO) can occur because this molecule quickly reacts with superoxide, forming peroxynitrite. Peroxynitrite is primarily responsible for the uncoupling of eNOS due to oxidation of the enzyme co-factor tetrahydrobiopterin (28). Furthermore, peroxynitrite can reduce vascular relaxation mediated by endothelium-derived hyperpolarizing factors through inhibition of large conductance of calcium-activated potassium channels (29).

In our study, deterioration in endothelial function was prevented by E2 therapy and by combined therapy with E2 + DRSP. Other synthetic progestins that are used in 

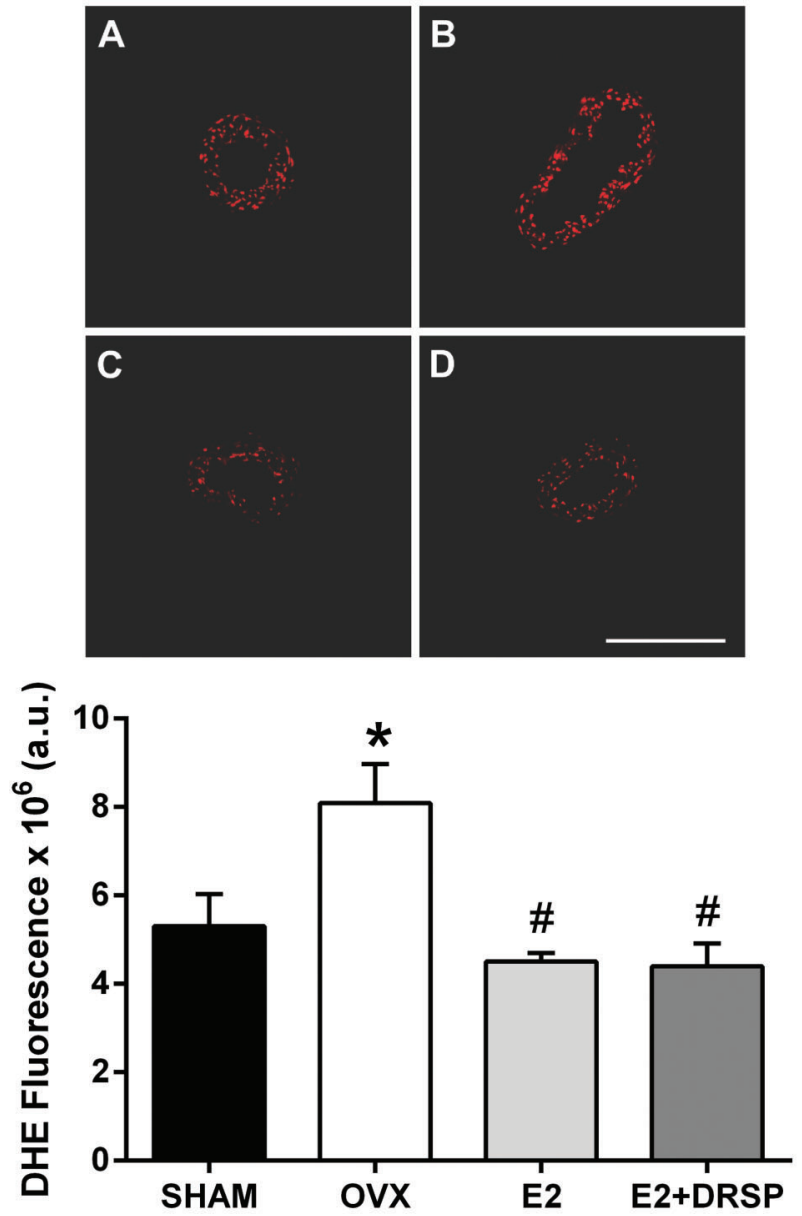

Figure 4. Analysis of oxidative stress in coronary arteries from ovariectomized spontaneously hypertensive rats by dihydroethidium fluorescence (DHE). Data are reported as means \pm SE $(n=4$ per group). Representative images of Sham $(A)$, OVX $(B)$, E2 $(C)$ and E2 + DRSP $(D)$ groups are shown. OVX: ovariectomized; E2: estrogen; DRSP: drospirenone. ${ }^{*} \mathrm{P}<0.05$ compared to Sham, ${ }^{\#} \mathrm{P}<0.05$ compared to OVX (one-way ANOVA followed by Tukey's post hoc test). Bar: $200 \mu \mathrm{m}$. a.u.: arbitrary units.

post-menopausal hormonal therapies, such as MPA, can impair or antagonize the beneficial actions of estradiol on vascular function (12). In the present study, combined therapy with E2+DRSP in spontaneously hypertensive rats demonstrated a more pronounced vasodilatory response because it was significantly greater at the three highest concentrations evaluated compared with OVX rats, suggesting that this progestin improves E2 effects on coronary function. Human studies assessing flowmediated dilation demonstrated that combined therapy can improve endothelium-dependent vascular function in young women and in healthy women in the postmenopausal period $(30,31)$.

Based on these previous findings, this study aimed to evaluate the endothelium-dependent pathway. We analyzed protein expression of the eNOS enzyme to verify if the effects of the therapies were associated with enhancement of this enzyme. However, we did not detect any differences in eNOS expression among the groups. This finding suggests that neither E2 nor E2 + DRSP can alter vascular expression of this enzyme. These results are in contrast with previous studies, which reported an increase in the expression of eNOS after OVX treatment in cerebral blood vessels and in culture of human endothelial cells $(32,33)$. Nevertheless, not all studies have reported an increase in eNOS after OVX and E2 treatment. A previous study from our laboratory also demonstrated no change in eNOS protein expression in coronary arteries after E2 treatment in OVX rats (7), and another study showed a reduction in eNOS expression in the aorta (26). However, in the present study, decreased expression of ER- $\alpha$ with OVX was restored by both treatments. Although we did not find any differences in eNOS expression among the groups, the increase in ER- $\alpha$ expression could explain, in part, the improved endotheliumdependent reactivity in the treated groups. This is mainly because the binding of E2 to this receptor can increase enzymatic activity of eNOS, augmenting NO release as previously reported by Chen et al. (34). Another important factor in our study was the reduction in vascular oxidative stress by the treatments because an increase in reactive oxygen species can reduce the bioavailability of $\mathrm{NO}$, as mentioned above.

Our results of protein expression, histomorphometry, and the reduction in oxidative stress appear to be more related to the effects mediated by E2 than those by DRSP. We did not detect any differences between the E2 and E2+DRSP groups on the parameters cited above, demonstrating a neutral effect of DRSP. However, our results are important because other synthetic progestins reduce endothelial expression of eNOS, which is associated with decreased NO production $(35,36)$. This phenomenon possibly culminates with degradation in vascular function. Accordingly, Arias-Loza et al. (12) demonstrated enhancement of vascular contraction in response to phenylephrine, as well as a reduction in endothelium-dependent and independent vascular relaxation of aortic rings when exposed to MPA.

According to previous studies, we suggest that factors other than NO may be associated with improvement of endothelium-mediated vasodilation in the E2+DRSP group. DRSP can increase the enzymatic activity of eNOS via the progesterone receptor, and in conjunction with E2, it can increase NO production (33). Moreover, inhibition of MR by DRSP causes augmentation of serum aldosterone concentrations $(16,37)$. Aldosterone activates rapid responses in vascular reactivity, which are not consistent with genomic activation (38). Gros et al. (39) showed in rat aortic rings that aldosterone significantly reduced constriction induced by phenylephrine. Another study reported that aldosterone acts as an endotheliumdependent vasodilator in rat cerebral and mesenteric arteries through $\mathrm{NO}(40)$. 
Therefore, taking into consideration inhibition of MR, based on our findings of an increase in serum aldosterone concentrations and a functional and intact endothelium, these factors could be possible mechanisms involved in improvement of endothelial vasodilation due to E2+ DRSP treatment. However, establishment of a causal relationship between these factors in hypertensive OVX rats and endothelium-dependent coronary vascular reactivity remains to be determined. Further studies on this issue are necessary.

This study showed that E2 + DRSP therapy, beyond the known effects on reduction of $\mathrm{BP}$, can improve

\section{References}

1. Wenger NK. Coronary heart disease: an older woman's major health risk. BMJ 1997; 315: 1085-1090, doi: 10.1136/ bmj.315.7115.1085.

2. Kearney PM, Whelton M, Reynolds K, Muntner P, Whelton PK, He J. Global burden of hypertension: analysis of worldwide data. Lancet 2005; 365: 217-223, doi: 10.1016/ S0140-6736(05)70151-3.

3. Barton M, Meyer MR. Postmenopausal hypertension: mechanisms and therapy. Hypertension 2009; 54: 11-18, doi: 10.1161/HYPERTENSIONAHA.108.120022.

4. Hernandez I, Delgado JL, Diaz J, Quesada T, Teruel MJ, Llanos $\mathrm{MC}$, et al. 17beta-estradiol prevents oxidative stress and decreases blood pressure in ovariectomized rats. Am J Physiol Regul Integr Comp Physiol 2000; 279: R1599-R1605.

5. Xu X, Xiao JC, Luo LF, Wang S, Zhang JP, Huang JJ, et al. Effects of ovariectomy and 17beta-estradiol treatment on the renin-angiotensin system, blood pressure, and endothelial ultrastructure. Int J Cardiol 2008; 130: 196-204.

6. Silva-Antonialli MM, Tostes RC, Fernandes L, Fior-Chadi $\mathrm{DR}$, Akamine $\mathrm{EH}$, Carvalho $\mathrm{MH}$, et al. A lower ratio of AT1/AT2 receptors of angiotensin II is found in female than in male spontaneously hypertensive rats. Cardiovasc Res 2004; 62: 587-593, doi: 10.1016/j.cardiores.2004. 01.020 .

7. Claudio ER, Endlich PW, Santos RL, Moyses MR, Bissoli NS, Gouvea SA, et al. Effects of chronic swimming training and oestrogen therapy on coronary vascular reactivity and expression of antioxidant enzymes in ovariectomized rats. PLoS One 2014; 8: e64806, doi: 10.1371/journal.pone.0064806.

8. Garcia PM, Gimenez J, Bonacasa B, Carbonell LF, Miguel SG, Quesada T, et al. 17beta-estradiol exerts a beneficial effect on coronary vascular remodeling in the early stages of hypertension in spontaneously hypertensive rats. Menopause 2005; 12: 453-459, doi: 10.1097/01.GME.0000 151654.10243.01.

9. Rossouw JE, Anderson GL, Prentice RL, LaCroix AZ, Kooperberg C, Stefanick ML, et al. Risks and benefits of estrogen plus progestin in healthy postmenopausal women: principal results From the Women's Health Initiative randomized controlled trial. JAMA 2002; 288: 321-333, doi: 10.1001/jama.288.3.321.

10. Sitruk-Ware R. Pharmacology of different progestogens: the special case of drospirenone. Climacteric 2005; 8 (Suppl 3): 4-12. endothelium-mediated vasodilation in the coronary bed and did not impair estrogenic effects on coronary vascular remodeling and oxidative stress in OVX spontaneously hypertensive rats. These results are of great importance considering that DRSP simultaneously acts in a similar manner as progesterone to protect against hyperplasia of the endometrium, and it can improve the beneficial cardiovascular effects observed in experimental models with estrogenic therapy. Therefore, hormonal therapy with E2 and DRSP may be an important therapeutic option in the prevention of coronary heart disease in hypertensive post-menopausal women.

11. Cox MW, Fu W, Chai H, Paladugu R, Lin PH, Lumsden AB, et al. Effects of progesterone and estrogen on endothelial dysfunction in porcine coronary arteries. J Surg Res 2005; 124: 104-111, doi: 10.1016/j.jss.2004.09.003.

12. Arias-Loza PA, Hu K, Schafer A, Bauersachs J, Quaschning $\mathrm{T}$, Galle J, et al. Medroxyprogesterone acetate but not drospirenone ablates the protective function of 17 betaestradiol in aldosterone salt-treated rats. Hypertension 2006; 48: 994-1001, doi: 10.1161/01.HYP.0000242482.57186.e8.

13. Perez-Lopez FR. Clinical experiences with drospirenone: from reproductive to postmenopausal years. Maturitas 2008; 60: 78-91, doi: 10.1016/j.maturitas.2008.03.009.

14. Losert W, Casals-Stenzel J, Buse M. Progestogens with antimineralocorticoid activity. Arzneimittelforschung 1985; 35: 459-471.

15. Genazzani AR, Mannella P, Simoncini T. Drospirenone and its antialdosterone properties. Climacteric 2007; 10 (Suppl 1): $11-18$.

16. White WB, Hanes V, Chauhan V, Pitt B. Effects of a new hormone therapy, drospirenone and 17-beta-estradiol, in postmenopausal women with hypertension. Hypertension 2006; 48: 246-253, doi: 10.1161/01.HYP.0000232179.60442.84.

17. Meendering JR, Torgrimson BN, Miller NP, Kaplan PF, Minson CT. A combined oral contraceptive containing $30 \mathrm{mcg}$ ethinyl estradiol and $3.0 \mathrm{mg}$ drospirenone does not impair endotheliumdependent vasodilation. Contraception 2010; 82: 366-372, doi: 10.1016/j.contraception.2010.03.009.

18. Cagnacci A, Ferrari S, Napolitano A, Piacenti I, Arangino S, Volpe A. Combined oral contraceptive containing drospirenone does not modify 24-h ambulatory blood pressure but increases heart rate in healthy young women: prospective study. Contraception 2013; 88: 413-417, doi: 10.1016/ j.contraception.2012.12.002.

19. Nisenbaum MG, de Melo NR, Giribela CR, de Morais TL, Guerra GM, de Angelis K, et al. Effects of a contraceptive containing drospirenone and ethinyl estradiol on blood pressure and autonomic tone: a prospective controlled clinical trial. Eur J Obstet Gynecol Reprod Biol 2014; 175: 62-66, doi: 10.1016/j.ejogrb.2014.01.006.

20. Saengsirisuwan V, Pongseeda S, Prasannarong M, Vichaiwong $\mathrm{K}$, Toskulkao C. Modulation of insulin resistance in ovariectomized rats by endurance exercise training and estrogen replacement. Metabolism 2009; 58: 38-47, doi: 10.1016/ j.metabol.2008.08.004. 
21. Santos RL, Abreu GR, Bissoli NS, Moyses MR. Endothelial mediators of 17 beta-estradiol-induced coronary vasodilation in the isolated rat heart. Braz J Med Biol Res 2004; 37 : 569-575, doi: 10.1590/S0100-879X2004000400014.

22. Lowry $\mathrm{OH}$, Rosebrough NJ, Farr AL, Randall RJ. Protein measurement with the Folin phenol reagent. $J$ Biol Chem 1951; 193: 265-275.

23. Borgo MV, Lopes AB, Gouvea SA, Romero WG, Moyses MR, Bissoli NS, et al. Effect of tamoxifen on the coronary vascular reactivity of spontaneously hypertensive female rats. Braz J Med Biol Res 2011; 44: 786-792, doi: 10.1590/ S0100-879X2011007500099.

24. Archer DF. Drospirenone and estradiol: a new option for the postmenopausal woman. Climacteric 2007; 10 (Suppl 1): 3-10.

25. McCurley A, Pires PW, Bender SB, Aronovitz M, Zhao MJ, Metzger $D$, et al. Direct regulation of blood pressure by smooth muscle cell mineralocorticoid receptors. Nat Med 2012; 18: 1429-1433, doi: 10.1038/nm.2891.

26. Florian M, Freiman A, Magder S. Treatment with 17-betaestradiol reduces superoxide production in aorta of ovariectomized rats. Steroids 2004; 69: 779-787, doi: 10.1016/ j.steroids.2004.09.008.

27. Strehlow K, Rotter S, Wassmann S, Adam O, Grohe C, Laufs K, et al. Modulation of antioxidant enzyme expression and function by estrogen. Circ Res 2003; 93: 170-177, doi: 10.1161/01.RES.0000082334.17947.11.

28. Laursen JB, Somers M, Kurz S, McCann L, Warnholtz A, Freeman BA, et al. Endothelial regulation of vasomotion in apoE-deficient mice: implications for interactions between peroxynitrite and tetrahydrobiopterin. Circulation 2001; 103 : 1282-1288, doi: 10.1161/01.CIR.103.9.1282.

29. Liu Y, Terata K, Chai Q, Li H, Kleinman LH, Gutterman DD. Peroxynitrite inhibits $\mathrm{Ca}^{2+}$-activated $\mathrm{K}^{+}$channel activity in smooth muscle of human coronary arterioles. Circ Res 2002; 91: 1070-1076, doi: 10.1161/01.RES.0000046003.14031.98.

30. Thompson AK, Przemska A, Vasilopoulou D, Newens KJ, Williams CM. Combined oral contraceptive pills containing desogestrel or drospirenone enhance large vessel and microvasculature vasodilation in healthy premenopausal women. Microcirculation 2011; 18: 339-346, doi: 10.1111/ j.1549-8719.2011.00094.x.

31. Villa P, Suriano R, Ricciardi L, Tagliaferri V, De Cicco S, De Franciscis $\mathrm{P}$, et al. Low-dose estrogen and drospirenone combination: effects on glycoinsulinemic metabolism and other cardiovascular risk factors in healthy postmenopausal women.
Fertil Steril 2011; 95: 158-163, doi: 10.1016/j.fertnstert.2010. 07.001.

32. McNeill AM, Zhang C, Stanczyk FZ, Duckles SP, Krause DN. Estrogen increases endothelial nitric oxide synthase via estrogen receptors in rat cerebral blood vessels: effect preserved after concurrent treatment with medroxyprogesterone acetate or progesterone. Stroke 2002; 33: 1685-1691, doi: 10.1161/01.STR.0000016325.54374.93.

33. Simoncini T, Fu XD, Caruso A, Garibaldi S, Baldacci C, Giretti MS, et al. Drospirenone increases endothelial nitric oxide synthesis via a combined action on progesterone and mineralocorticoid receptors. Hum Reprod 2007; 22: 2325-2334, doi: 10.1093/humrep/dem109.

34. Chen Z, Yuhanna IS, Galcheva-Gargova Z, Karas RH, Mendelsohn ME, Shaul PW. Estrogen receptor alpha mediates the nongenomic activation of endothelial nitric oxide synthase by estrogen. J Clin Invest 1999; 103: 401406, doi: $10.1172 / \mathrm{JCl} 5347$.

35. Zerr-Fouineau M, Chataigneau M, Blot C, Schini-Kerth VB. Progestins overcome inhibition of platelet aggregation by endothelial cells by down-regulating endothelial NO synthase via glucocorticoid receptors. FASEB J 2007; 21: 265-273, doi: 10.1096/fj.06-6840com.

36. Zerr-Fouineau M, Jourdain M, Boesch C, Hecker M, Bronner $C$, Schini-Kerth VB. Certain progestins prevent the enhancing effect of 17beta-estradiol on NO-mediated inhibition of platelet aggregation by endothelial cells. Arterioscler Thromb Vasc Biol 2009; 29: 586-593, doi: 10.1161/ ATVBAHA.108.178004.

37. Oelkers W, Berger V, Bolik A, Bahr V, Hazard B, Beier S, et al. Dihydrospirorenone, a new progestogen with antimineralocorticoid activity: effects on ovulation, electrolyte excretion, and the renin-aldosterone system in normal women. $J$ Clin Endocrinol Metab 1991; 73: 837-842, doi: 10.1210/jcem-73-4-837.

38. Feldman RD, Gros R. Unraveling the mechanisms underlying the rapid vascular effects of steroids: sorting out the receptors and the pathways. Br J Pharmacol 2011; 163: 1163-1169.

39. Gros R, Ding Q, Liu B, Chorazyczewski J, Feldman RD. Aldosterone mediates its rapid effects in vascular endothelial cells through GPER activation. Am J Physiol Cell Physiol 2013; 304: C532-C540, doi: 10.1152/ajpcell.00203.2012.

40. Heylen E, Huang A, Sun D, Kaley G. Nitric oxide-mediated dilation of arterioles to intraluminal administration of aldosterone. J Cardiovasc Pharmacol 2009; 54: 535-542, doi: 10.1097/FJC.0b013e3181bfb00d. 